\title{
Filling the Gaps for Enhancing the Effectiveness of Community-Based Programs Combining Treatment and Prevention of Child Malnutrition: Results from the Rainbow Project 2015-17 in Zambia
}

\author{
Stefania Moramarco 1,2 (D), Giulia Amerio ${ }^{2}$, Jean Kasengele Chipoma ${ }^{3}$, Karin Nielsen-Saines ${ }^{4, *}$, \\ Leonardo Palombi ${ }^{1}$ and Ersilia Buonomo ${ }^{1}$ \\ 1 Department of Biomedicine and Prevention, University of Rome Tor Vergata, via Montpellier, \\ Rome 00133, Italy; stefania.moramarco@gmail.com (S.M.); palombi@uniroma2.it (L.P.); \\ ersilia.buonomo@uniroma2.it (E.B.) \\ 2 Rainbow Project Association Pope John 23rd, 5656 Chinika Road, Ndola 10101, Zambia; \\ giulia.amerio@gmail.com \\ 3 Ndola District Health Office, 1307 Naidu Close, Ndola 10101, Zambia; jeankasengele@gmail.com \\ 4 Department of Pediatrics, David Geffen UCLA School of Medicine School of Medicine, Los Angeles, \\ CA 90095, USA \\ * Correspondence: knielsen@mednet.ucla.edu; Tel.: +1-310-825-5235
}

Received: 1 June 2018; Accepted: 12 August 2018; Published: 22 August 2018

\begin{abstract}
Background: Child malnutrition, in all its forms, is a public health priority in Zambia. After implementations based on a previous evaluation in 2012-14 were made, the efficacy of the Rainbow Project Supplementary Feeding Programs (SFPs) for the integrated management of severe acute malnutrition (SAM), moderate acute malnutrition (MAM), and underweight was reassessed in 2015-17. Methods: The outcomes were compared with International Standards and with those of 2012-14. Cox proportional risk regression analysis was performed to identify predictors of mortality and defaulting. Results: The data for 900 under-five year-old malnourished children were analyzed. Rainbow's 2015-17 outcomes met International Standards, for total and also when stratified for different type of malnutrition. A better performance than 2012-14 was noted in the main areas previously identified as critical: mortality rates were halved ( $5.6 \%$ vs. $3.1 \%, p=0.01)$; significant improvements in average weight gain and mean length of stay were registered for recovered children $(p<0.001)$. HIV infection (5.5; 1.9-15.9), WAZ <-3 (4.6; 1.3-16.1), and kwashiorkor (3.5; 1.2-9.5) remained the major predictors of mortality. Secondly, training community volunteers consistently increased the awareness of a child's HIV status $(+30 \% ; p<0.001)$. Conclusion: Rainbow SFPs provide an integrated community-based approach for the treatment and prevention of child malnutrition in Zambia, with its effectiveness significantly enhanced after the gaps in activities were filled.
\end{abstract}

Keywords: child malnutrition; community-based management of acute malnutrition-CMAM; moderate acute malnutrition-MAM; severe acute malnutrition—SAM; supplementary feeding programs-SFP; underweight; Zambia

\section{Introduction}

Childhood malnutrition remains a major public health problem throughout the developing world, being the underlying factor for nearly half of all yearly under-5 deaths from preventable causes [1]. It is estimated that more than 50 million children worldwide are affected by acute malnutrition, with 16 million having Severe Acute Malnutrition (SAM) and a further 33 million having Moderate 
Acute Malnutrition (MAM) [2]. Acute malnutrition, if untreated, is an attributable cause of death; $12.6 \%$ of the 6.9 million deaths worldwide among children under five years of age are due to acute malnutrition [3]. The community-based management of acute malnutrition (CMAM) is unequivocally advocated as an effective program to address acute malnutrition in children aged 6 to 59 months and it is globally implemented in 55 countries. This approach, which provides services to local communities by decentralized treatment points within existing healthcare facilities, is widely used across multiple humanitarian agencies both for SAM and MAM [4-6]. Within the CMAM, targeted Supplementary Feeding Programs (SFPs) are recognized as best practice for treating MAM and preventing the deterioration into SAM in the emergency nutrition response [7]. However, more evidence-based research is needed to evaluate the effectiveness of a combined approach integrating preventive and curative interventions [8], adapted to different scenarios and non-emergency settings [6].

In Zambia, malnutrition remains one of the most serious problems among children under five years of age. This condition is estimated to underlie 52\% of all under-five deaths [9] (64 per 1000 live births in 2015) [10]. In 2015, the wasting prevalence in Zambia was 6.3\% [11], which was off course from the World Health Assembly Nutrition target to "reduce and maintain childhood wasting to less than $5 \%$ by 2025 " [12]. The picture of malnutrition has been exacerbated by high rates of HIV / AIDS (UNAIDS estimates that 85,000 children below 14 years of age were HIV infected in 2015 [13]) and by an exponential rise in tuberculosis (TB) over the last 3 decades, with children accounting for $<10 \%$ of incident TB cases annually [14], more than $50 \%$ of whom are HIV co-infected [15,16]. Traditional CMAM is not widely available in the country and most areas are not covered by nutrition-specific interventions targeting acute malnutrition [17]. However, the Zambian Government still remains committed to the scale-up provision of high impact services with a special focus on maternal and child health [18]. In the Ndola area, the Rainbow Project, under the Association Pope John 23rd, is the only locally well-implemented program with an integrated community-based approach for the management of child malnutrition that combines MAM/SAM/underweight treatment and prevention, operating through the SFPs since 1998 [19].

The aim of the current study was primarily to demonstrate the Rainbow SFPs' effectiveness in the community-based management of child malnutrition in Zambia, by presenting an innovative approach run by well-trained community volunteers, integrating treatment and prevention of MAM, SAM, and being underweight. Therefore, program outcomes between the years of 2015-17 were evaluated and compared with International Standards and previous study results (Rainbow 2012-14), after filling the gaps in prior activities [20]. Secondly, the current study aimed to demonstrate that Rainbow SFPs can act as an integrated program for nutrition and child health promotion, coupling growth surveillance with HIV counseling and diagnosis, facilitating access to HIV / TB treatment and overall care for Zambian children.

\section{Materials and Methods}

\subsection{Setting}

The Rainbow Project operates 11 SFPs for Zambian malnourished children (ages 6-59 months) in the Ndola area (9 located in urban areas: Twapia, Nkwazi, Kabushi, Kaloko, Kawama, Chifubu, Pamodzi, Kanyala and Mackenzie; 2 located in rural areas: Baluba and Chikumbi) with a particular focus on community mobilization and capacity building activities. All of the centers are run by leaders of small NGOs and Community-based Organizations (CBOs), and are coordinated by professionals of the Rainbow Office, in close network with health facilities, local clinics running Outpatient Therapeutic Programs (OTP), the Children's Hospital, the Ndola District Health Management Teams (DHMTs), and other local authorities. In CMAM programs, children with MAM are the main target of SFPs, while SAM rehabilitation is addressed by OTPs and/or Inpatient Care (IC) [21,22]. However, within the Zambian context, since the access to OTP/IC is restricted and/or the supply of ready-to-use therapeutic food (RUTF) is erratic in most areas in which Rainbow operates, children with SAM are 
enrolled in Rainbow SFPs, in addition to referral to OTP/IC as the best practice. This choice has been made for ethical and humanitarian reasons, in order to facilitate the access of children/families most in need to nutritional supplementation, health education and all the other activities that are part of the Rainbow approach. Children who are underweight are enrolled in the program with the viewpoint that optimizing healthy child growth and improving nutritional status can have an impact on reducing and preventing rates of wasting $[23,24]$. Therefore, Rainbow SFPs provide an effective integrated approach for child malnutrition management, combining treatment and the prevention of MAM/SAM/and being underweight.

\subsection{Rainbow SFPs Activities}

Rainbow SFPs' protocol includes both nutrition-specific or direct interventions (growth monitoring and supplementary food) and nutrition-sensitive or indirect interventions (nutritional counseling, health skills for guardians, and child health promotion). Nutrition-specific activities (anthropometric assessment, on-site feeding, cooking demonstrations, food handouts: local food-maize flour, groundnuts, sugar, oil—and a packaged fortified blended flour-high energy protein supplement/HEPS made with maize, soya and enriched with vitamins and minerals), coupled by nutrition-sensitive interventions (nutritional counseling and health education) are performed on a weekly basis. The food schedule was recently revised in order to improve the quantity and quality of high energy protein supplement/HEPS from the previous rations of 2012-14: the amount of HEPS distributed was redoubled for providing a daily ration of $150 \mathrm{~g}$; and guardians/mothers were counseled to add sugar and oil when cooking it $[23,25]$. In Rainbow's SFPs, all the children receive the same food supplements, regardless of the type of malnutrition and/or simultaneous admission in OTP.

All community volunteers/operators are appropriately trained and constantly updated in Infant and Young Child Feeding (IYCF) practices promoted by the Zambian Government.

Supporting HIV voluntary counseling and testing (VCT) and active HIV case-finding are also part of the SFP routine activities. Guardians/mothers of children with an unknown HIV status at the time of admission are counseled and encouraged to go to the nearest health facility for an HIV test for both mother and child. Personnel are trained in confidentiality issues (e.g., counseling in the context of prevention of mother-to-child transmission PMTCT), with specific refresher courses attended within the last years.

Home visits performed by community volunteers during nutritional rehabilitation are necessary to encourage good adherence to treatment and to tackle determinants of malnutrition at the household level.

Revision of the food schedule (doubling HEPS quantity and improving quality) and staff training support in HIV counseling and testing were the two main activities implemented during the last two years, after critical areas for improvement were identified during the previous program evaluation in 2012-14 [20]. Nutritional counseling, emphasizing the use of locally available food, was also integrated as a routine activity of the SFPs, with pilot study results discussed elsewhere [26].

\subsection{Study Population and Data Collection}

Data on Zambian malnourished children followed from July 2015 to April 2017 in the Rainbow Project SFPs were analyzed using a community-based retrospective observational cohort study design. General pediatric information and socio-demographic characteristics, health and nutritional parameters were entered in a register created ad hoc for the project. General information included the date of birth, age, gender, and sibling count. Socio-demographic data recorded included the family history (parents' marital status, relationship, and age of the guardian) and housing information (area of stay, address, household conditions). The health information included disability, medical complications and/or illness, enrollment in OTP, and HIV status. The latter (HIV status), was ascertained from the prevention mother-to-child transmission (PMTCT) section of the child under-five card released from the primary health care facilities of the Zambia Health Ministry. A color code was assigned to sensitive information (such as HIV status). Nutritional parameters included anthropometric measurement (weight, MUAC, edema). The data were registered after verbal consent 
of caregivers and in full respect of confidentiality and they were then collected from different sites and entered into a database with the removal of personal identifiers.

\subsection{Anthropometric Assessment and Malnutrition Classification}

Malnourished children enrolled in Rainbow SFPs were recruited through community outreaches or referred from local health facilities. The anthropometric assessment consisted in measuring weight, Mid-Upper Arm Circumference (MUAC), and checking for bilateral pitting edema. Children were assessed without clothes or footwear; their weight (in kilograms) was measured using a mechanical baby scale graduated by $0.1 \mathrm{~kg}$ increments (salter 235). MUAC (in centimeters) was measured using a simple colored plastic strip (standardized UNICEF tape). Bilateral pitting edema was checked by applying gentle thumb pressure on the dorsum of the feet and assessing for residual depression; edema was detected as different grades.

The children were admitted to SFPs by using a two-priority criteria system of enrollment: first priority was given to acute malnutrition (SAM or MAM) and second priority to underweight status. Definition of SAM (MUAC $\leq 11.5 \mathrm{~cm}$, and/or edema) and MAM (MUAC $>11.5$ and $\leq 12.5$ ) was made according to the WHO/UNICEF criteria [27] and the Integrating Management of Acute Malnutrition (IMAM) guidelines of the Zambian Ministry of Health [28] for children aged 6 to 59 months. As recently indicated in the updated WHO guidelines, in order to achieve the early community identification of malnourished children, Rainbow community volunteers measured the MUAC and examined children for pitting edema, reserving the assessment of weight for height and weight for length (WHZ/WLZ) within primary health care facilities and hospitals [29]. Underweight was defined as a weight-for-age Z-score (WAZ) $<-2$ [30].

If a child qualified at the same time for different criteria, the enrollment in SFPs was made considering the most severe condition of malnutrition. All children with MAM or being underweight without health complications were enrolled directly, while when reporting health complications they were first referred to the nearest health facility for medical care. If the child was found to have SAM without medical complications (either marasmus or kwashiorkor grade 1 and 2), he/she was primarily enrolled in OTP following the best practice guidelines [28]. Simultaneously those children were enrolled in SFP for ethical reasons, as previously reported. If the health staff identified a child as having SAM with medical complications, he/she was referred to the Arthur Davidson Children's Hospital for IC and then returned to Rainbow SFP when discharged from the IC. All children stayed in the program until the SFP discharge criteria were met: for two consecutive weeks the MUAC should be $>12.5 \mathrm{~cm}$, the edema should be absent, or there should be a $15 \%$ weight gain to be considered if being underweight was the admission criteria [23].

\subsection{Program Outcomes and Performance Indicators}

Standard outcomes included recovery rate, death rate, and default rate. Recovered/cured was defined as an individual who met the discharge criteria. Defaulter was defined as a child lost to follow up for three consecutive weeks. A child was classified as a "defaulter" when he/she dropped out of the study due to refusal or it was not possible to locate the child and make a home assessment. Death was registered when occurring during the time the patient was enrolled in the program. Early mortality and defaulting (within 15 days from enrollment) were excluded because they might not be directly attributable to the performance of the SFPs. Individuals who did not complete their rehabilitation because they moved to another area were considered transferred; this outcome was not included in the performance evaluation because of the current absence of published targets. The length of stay and weight gain were considered additional indicators for targeted SFPs. The mean length of stay expressed the time of stay for recovered children; the mean weight gain expressed the average number of grams gained per kilograms per day among children who were cured. For humanitarian and ethical reasons, nutritional treatment was provided until children reached the recovery goals (treat-to-goal), so none were categorized as non-cured/non-responder (defined as cases that did not reach discharge 
criteria after a pre-defined length of time). The program outcomes were compared with exit categories for targeted SFPs from the Sphere Project (recovery, death, and defaulter rate) and UNHCR guidelines (mean length of stay, and average weight gain). The Sphere Standards are the typical criteria used for assessing the effectiveness of SFP [31]. The UNHCR guidelines are intended as a practical guide to design, implement, monitor, and evaluate selective feeding programs in emergency situations [23]. In addition, outcomes of Rainbow 2015-17 were compared with those previously published in 2012-14, in order to evaluate the impact of adjustments on the program performance.

\subsection{Statistical Analysis}

The data were extracted from the Rainbow database and analyzed using the SPSS software system 21.0 (IBM, Somers, NY, USA). Weight-for-age Z-scores (WAZ) and MUAC-for-age Z-scores (ZMUAC) were calculated using the WHO Anthro Software (Version 3.2.2, January 2011, WHO, Geneva, Switzerland) [32]. Descriptive data and variables measured were presented as means with standard deviations (SD). The Odds ratios 95\% Confidence Intervals (OR; 95\% CI) were calculated between age and general acute malnutrition, and between different types of severe acute malnutrition (marasmus and kwashiorkor) and length of stay. A descriptive analysis was performed for the entire study population to estimate the proportion of children who recovered, died, and defaulted during the intervention phase. Rainbow 2015-17 outcomes were compared with those of Rainbow 2012-14, with student $t$-tests for assessing the statistical significance of differences between continuous variables and Z-test for independent proportions. Univariate and multivariate Cox regressions were performed to identify the main predictors of mortality and defaulting (hazard ratio: HR, 95\% CI). Because there were multiple independent variables, a stepwise forward regression approach was used.

\section{Results}

Data on 1264 malnourished Zambian children (6-59 months) who were seen between July 2015 and April 2017 were extracted from the database. Children still on rehabilitation at the moment of the study were excluded from the analysis. Formally transferred, early mortality, and early defaulting episodes (occurred within 2 weeks from admission) were not included. Eleven cases were excluded from the analysis because their records either had incomplete or missing baseline information. Therefore, the overall sample analyzed 900 children, all with accurate and complete information relevant to measuring the outcome of the intervention (Figure 1).

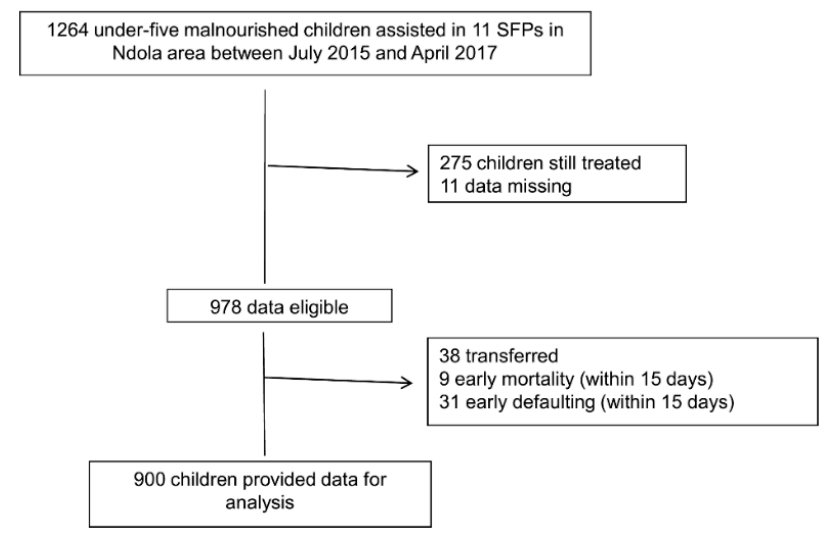

Figure 1. The study flowchart.

The main socio-demographic characteristics of the enrolled children in 2015-17, comorbidity and nutritional status at baseline, are reported in Table 1, and compared with data for 2012-14 previously published [20]. All children came from low socio-economic households. The youngest children ( $<18$ months of age) were more likely to be affected by general acute malnutrition (OR 3.2, 
CI: 2.4-4.2), with more than $90 \%$ of children with kwashiorkor being less than 29 months of age. The high prevalence of kwashiorkor found at admission (20.4\%) was consistent with the proportion of SAM cases presented in the annual Zambia country report [33].

Table 1. The socio-demographic, health and nutritional characteristics of children at the baseline, Rainbow 2015-17 and 2012-14.

\begin{tabular}{|c|c|c|}
\hline Variables & Value $2015-17$ & Value 2012-14 \\
\hline Male, n. (\%) & $439(48.8)$ & $428(49.9)$ \\
\hline Age in months, mean $\pm \mathrm{SD}$ & $19.7 \pm 9.9$ & $19 \pm 9.4$ \\
\hline$<18$ months of age & $452(50.2)$ & $455(53)$ \\
\hline Rural area, n. (\%) & $139(15.4)$ & $163(19)$ \\
\hline \multicolumn{3}{|l|}{ Parental status, n. (\%) } \\
\hline Orphans of one parent & $32(3.6)$ & $33(3.9)$ \\
\hline Orphans of both parents & $15(1.7)$ & $15(1.7)$ \\
\hline Single guardian & $238(26.4)$ & NA \\
\hline Disability, n. (\%) & $23(2.6)$ & NA \\
\hline Twin, n. (\%) & $42(4.7)$ & $62(7.2)$ \\
\hline Caregiver's age, mean \pm SD [min-max] & $\begin{array}{c}28.4 \pm 9.2 \\
{[15-69]}\end{array}$ & $\begin{array}{l}29 \pm 10 \\
{[13-78]}\end{array}$ \\
\hline \multicolumn{3}{|l|}{ Referred from, n. (\%) } \\
\hline Hospital & $23(2.6)$ & $46(5.4)$ \\
\hline Local health facility & $186(20.7)$ & $279(32.5)$ \\
\hline Community & $691(76.7)$ & $533(62.1)$ \\
\hline \multicolumn{3}{|l|}{ HIV status, n. (\%) } \\
\hline Infected & $25(2.8)$ & $51(5.9)$ \\
\hline Uninfected & $541(60.1)$ & $426(49.7)$ \\
\hline Status unknown & $334(37.1)$ & $381(44.4)$ \\
\hline Non-breastfed children, $\mathrm{n} .(\%)$ & $564(62.7)$ & NA \\
\hline Months of age, mean \pm SD & $14.9 \pm 6.9$ & \\
\hline Admission criteria: MAM, n. (\%) & $242(26.9)$ & $323(37.6)$ \\
\hline$<18$ months of age & $145(59.9)$ & $195(60.4)$ \\
\hline Admission criteria: SAM, n. (\%) & $346(38.4)$ & $241(28.1)$ \\
\hline$<18$ months of age & $207(59.8)$ & $146(60.6)$ \\
\hline Admission criteria: Underweight, n. (\%) & $312(34.7)$ & $294(34.3)$ \\
\hline$<18$ months of age & $100(32.1)$ & $114(38.8)$ \\
\hline Presence of edema, n. (\%) & $184(20.4)$ & $77(9)$ \\
\hline Relapses of malnutrition event, n. (\%) & $129(14.3)$ & $68(7.9)$ \\
\hline Weight $(\mathrm{kg})$, mean $\pm \mathrm{SD}$ & $7.6 \pm 1.5$ & $7.8 \pm 1.6$ \\
\hline $\mathrm{WAZ}$, mean $\pm \mathrm{SD}$ & $-3.1 \pm 0.9$ & $-2.8 \pm 1.1$ \\
\hline $\operatorname{MUAC}(\mathrm{cm})$, mean $\pm \mathrm{SD}$ & $12.2 \pm 1$ & $12.4 \pm 1$ \\
\hline ZMUAC, mean \pm SD & $-2.4 \pm 1$ & NA \\
\hline Health problems, n. (\%) & 429 (47.7) & $299(34.9)$ \\
\hline Fever & $75(8.3)$ & $73(8.5)$ \\
\hline Diarrhea & $118(13.1)$ & $71(8.3)$ \\
\hline Lack of appetite & $124(13.8)$ & $66(7.7)$ \\
\hline Cough/Sneezing & $99(11)$ & $28(3.3)$ \\
\hline Malaria & $4(0.4)$ & $7(0.8)$ \\
\hline Others & $9(1.1)$ & $54(6.3)$ \\
\hline
\end{tabular}

MAM = moderate acute malnutrition; MUAC = mid-upper arm circumference; $S A M=$ severe acute malnutrition; $\mathrm{WAZ}=$ weight for age Z-score; $\mathrm{ZMUAC}=\mathrm{MUAC}$ for age $\mathrm{Z}$-score.

\subsection{First Results: Program Performance and Anthropometric Analysis}

We evaluated the Rainbow 2015-17 outcomes and compared the results either with those of Rainbow 2012-14 and with the International Sphere Standards/UNHCR indicators, only available for SAM and MAM (Table 2). 
Table 2. The Rainbow 2012-14 vs. 2015-17 outcomes, and the International Standards.

\begin{tabular}{|c|c|c|c|c|c|c|c|c|c|c|c|}
\hline \multirow[b]{2}{*}{ Indicators } & \multicolumn{3}{|c|}{ Total } & \multicolumn{3}{|c|}{ MAM } & \multicolumn{3}{|c|}{ SAM } & \multicolumn{2}{|c|}{$\begin{array}{l}\text { International Standards (Sphere } \\
\text { Project/UNHCR) [23,31] }\end{array}$} \\
\hline & $\begin{array}{c}\text { Rainbow } \\
\text { 2012-14 } \\
\text { (n.858) }\end{array}$ & $\begin{array}{c}\text { Rainbow } \\
\text { 2015-17 } \\
\text { (n.900) }\end{array}$ & $p$-Value & $\begin{array}{c}\text { Rainbow } \\
\text { 2012-14 } \\
\text { (n.323) }\end{array}$ & $\begin{array}{l}\text { Rainbow } \\
\text { 2015-17 } \\
\text { (n.242) }\end{array}$ & $p$-Value & $\begin{array}{c}\text { Rainbow } \\
2012-14 \\
\text { (n.241) }\end{array}$ & $\begin{array}{c}\text { Rainbow } \\
\text { 2015-17 } \\
\text { (n.346) }\end{array}$ & $p$-Value & Acceptable & Alarming \\
\hline Recovered, n. (\%) & 709 (82.6) & $771(85.7)$ & 0.08 & $278(86.1)$ & $219(90.5)$ & 0.1 & $177(73.5)$ & $284(82.1)$ & 0.01 & $>75 \%$ & $<50 \%$ \\
\hline Defaulters, n. (\%) & $101(11.8)$ & $101(11.2)$ & 0.72 & $36(11.1)$ & $17(7)$ & 0.09 & $34(14.1)$ & $41(11.8)$ & 0.42 & $<15 \%$ & $>30 \%$ \\
\hline Deaths, n. (\%) & $48(5.6)$ & $28(3.1)$ & 0.01 & $9(2.8)$ & $6(2.5)$ & 0.8 & $30(12.4)$ & $21(6.1)$ & 0.006 & $\begin{array}{l}<3 \% \text { for SFPs } \\
<10 \% \text { for TFPs }\end{array}$ & $>10 \%$ \\
\hline $\begin{array}{l}\text { Mean length of stay, } \\
\text { weeks (SD) }\end{array}$ & $19.3 \pm 11.5$ & $16.6 \pm 9.6$ & $<0.001$ & $19.3 \pm 11.9$ & $13.1 \pm 7.4$ & $<0.001$ & $22 \pm 11.8$ & $15.9 \pm 9.6$ & $<0.001$ & $\begin{array}{r}<12 \\
<3-4 \text { weeks for } \\
<60 \text { days for TFP }\end{array}$ & $\begin{array}{l}\text { FPs } \\
\text { I full recovery) } \\
\text { TPs combined) }\end{array}$ \\
\hline $\begin{array}{l}\text { Average weight gain, } \\
\text { g/kg/day (SD) }\end{array}$ & $1.7 \pm 1.2$ & $2 \pm 1.5$ & $<0.001$ & $1.7 \pm 1$ & $1.9 \pm 1.2$ & 0.03 & $2 \pm 1.3$ & $2.4 \pm 1.7$ & 0.007 & $\begin{array}{r}\geq 3 \mathrm{~g} / \\
\geq 8 \mathrm{~g} / \mathrm{kg} / \text { day for } \\
\geq 4 \mathrm{~g} / \mathrm{kg} / \text { day for } \mathrm{T}\end{array}$ & $\begin{array}{l}\text { SFPs } \\
\text { ill full recovery) } \\
\text { OTPs combined) }\end{array}$ \\
\hline
\end{tabular}

$\overline{\mathrm{IC}}=$ inpatient care; MAM = moderate acute malnutrition; OTPs = outpatient therapeutic programs; SAM = severe acute malnutrition; SFPs = supplementary feeding programs; TFPs = Therapeutic feeding programs. 
The three main core performance outcomes (recovery, death, and defaulter rate) met the Sphere Standards, either for general or when SAM and MAM outcomes were split.

General improvements in all rates of these main indicators were noted when compared with Rainbow 2012-14, with a statistically significant increase in recovery rate for SAM $(p=0.01)$. Halving the mortality rates was the main goal achieved since in the first evaluation it was above the targets; for total: 5.6\% in Rainbow 2012-14 vs. 3.1\% in Rainbow 2015-17, $p=0.01$; for SAM: $12.4 \%$ in Rainbow $2012-14$ vs. $6.7 \%$ in Rainbow $2015-17, p=0.006$. The mean length of stay was above the UNHCR target, although for MAM the mean length of stay was exceeded the International standard only for one week (13.1 weeks $\pm 7.4 \mathrm{SD}$ ). A longer period of recovery was needed by children with SAM (+4 weeks), with marasmatic children more likely to stay longer (OR 2.3, CI: 1.6-3.4), while children having kwashiorkor resolved edema earlier (OR 0.4, CI: 0.3-0.6). As compared to Rainbow 2012-14, a reduction in the mean length of stay was noted either for the total or for the two malnutrition groups $(p<0.001)$.

Despite daily gains in mean grams per weight $(2 \mathrm{~g} / \mathrm{kg} /$ day $\pm 1.5 \mathrm{SD})$, this measure was still below the international target of $\geq 3 \mathrm{~g} / \mathrm{kg}$ /day for SFPs. Nevertheless, our findings are in line with reviews of the literature (between 1 and $2 \mathrm{~g} / \mathrm{kg} /$ day) where programs supplemented with corn/soy blended flour (CSB) were evaluated $[25,34]$. We believe that sharing food within the household could have been a potential explanation for the quite poor mean weight gain since it is a common cultural practice, especially in food insecurity contexts [35]. Children admitted with SAM had higher weight gains then those with MAM, which might be due to simultaneous consumption of RUTF, even if erratic. A statistically significant increase in the average weight gain was noted when the outcomes were compared with that of Rainbow 2012-14 due to the new food schedule that allowed a reduction in the mean length of stay for recovered children, as proposed in the previous study [22].

As novel aspects of the community-based management of child malnutrition, Rainbow SFPs have been effective even in the nutritional rehabilitation of those children, although International guidelines do not provide specific targets for children who are underweight: $85.9 \%$ recovered; $13.8 \%$ defaulters; $0.3 \%$ deaths; average weight gain $1.7 \mathrm{~g} / \mathrm{kg} /$ die $\pm 1.3 \mathrm{SD}$; mean length of stay 20.3 weeks $\pm 10 \mathrm{SD}$.

To identify the main predictors of mortality and defaulting, we performed univariate and multivariate (forward stepwise model) Cox proportional risk regression analyses (HR, 95\% CI). The available characteristics at baseline and nutritional response to rehabilitation were analyzed separately (Table 3). Baseline characteristics included in the multivariate analysis were age below 18 months, socio-demographic conditions (rural area, orphan), HIV infection, anthropometric assessment (nutritional edema, WAZ $<-3$, ZMUAC $<-2$ ) and health problems at admission. Nutritional rehabilitation included gains in anthropometric parameters during the admission in the SFPs (WAZ gain, weight gain, ZMUAC gain).

The HIV infection still remained the major predictor of mortality (HR 5.5; CI: 1.9-15.9), together with SAM, defined as kwashiorkor (HR 3.5; CI: 1.2-9.5). Nutritional edema was associated with a high risk of mortality, and confirmed the importance of kwashiorkor as a public health problem, but was often not perceived as worrisome by guardians [33]. Severe underweight status at admission (WAZ $<-3$ ) also posed a greater risk of death (HR 4.6; CI: 1.3-16.1). This result was in line with the previous Rainbow study and highlighted the premise that the prevention and management of underweight status, considered a second priority criterion of admission, should be recognized as an essential part of the program against childhood malnutrition [23,24]. Compared to Rainbow 2012-14, predictors of mortality were no longer noted to be risk factors for defaulting. We identified that living in the rural area (HR 2.3; CI: 1.3-4.2) and being an orphan of any parent (HR 3.2; CI: 1.5-6.8) were the only two baseline variables associated with defaulting. Considering the nutritional response to treatment, the poor gain in any anthropometric parameters was independently associated either with case-fatality or defaulting. Specifically, when considering the multivariate Cox analysis, low weight gain and ZMUAC gain were more predictive of mortality, while poor WAZ gain and ZMUAC gain of defaulting. 
Table 3. The predictors of mortality and defaulting. Cox proportion risk analysis.

\begin{tabular}{|c|c|c|c|c|c|c|c|c|c|c|c|c|c|}
\hline & & \multicolumn{6}{|c|}{ Predictors of Mortality } & \multicolumn{6}{|c|}{ Predictors of Defaulting } \\
\hline & & \multicolumn{3}{|c|}{ Univariate Analysis } & \multicolumn{3}{|c|}{ Multivariate Analysis } & \multicolumn{3}{|c|}{ Univariate Analysis } & \multicolumn{3}{|c|}{ Multivariate Analysis } \\
\hline & & HR & $95 \% \mathrm{CI}$ & $p$-Value & HR $\operatorname{Exp}(B)$ & $95 \% \mathrm{CI}$ & $p$-Value & HR & $95 \% \mathrm{CI}$ & $p$-Value & HR Exp (B) & $95 \% \mathrm{CI}$ & $p$-Value \\
\hline \multirow{8}{*}{ Baseline characteristics } & Age $<18$ months & 1.04 & $0.49-2.19$ & 0.917 & - & - & - & 0.83 & $0.56-1.23$ & 0.350 & & & \\
\hline & Rural Area & 0.24 & $0.03-1.78$ & 0.164 & - & - & - & 2.48 & $1.61-3.82$ & $<0.001$ & 2.31 & $1.27-4.21$ & 0.006 \\
\hline & Orphan & 1.69 & $0.40-7.14$ & 0.473 & - & - & - & 2.41 & $1.26-4.64$ & 0.008 & 3.22 & $1.52-6.81$ & 0.002 \\
\hline & HIV infection & 8.11 & $2.85-23.04$ & $<0.001$ & 5.53 & $1.92-15.94$ & 0.002 & 1.02 & $0.32-3.27$ & 0.968 & - & - & - \\
\hline & $\mathrm{WAZ}<-3$ & 9.37 & $2.83-31.06$ & $<0.001$ & 4.57 & $1.30-16.11$ & 0.018 & 1.01 & $0.51-2.00$ & 0.983 & - & - & - \\
\hline & ZMUAC $<-2$ & 8.11 & $1.92-34.20$ & 0.004 & - & - & - & 1.50 & $0.99-2.30$ & 0.062 & - & - & - \\
\hline & Kwashiorkor/edema & 4.59 & $2.14-9.85$ & $<0.001$ & 3.51 & $1.29-9.51$ & 0.014 & 1.10 & $0.65-1.86$ & 0.724 & - & - & - \\
\hline & Health problems & 1.75 & $0.82-3.73$ & 0.149 & - & - & - & 1.34 & $0.91-1.99$ & 0.140 & - & - & - \\
\hline \multirow{3}{*}{$\begin{array}{l}\text { Nutritional response } \\
\text { characteristics }\end{array}$} & Weight gain (g/kg/die) & 0.42 & $0.34-0.51$ & $<0.001$ & 0.59 & $0.48-0.74$ & $<0.001$ & 0.57 & $0.49-0.65$ & $<0.001$ & - & - & - \\
\hline & WAZ gain & 0.17 & $0.12-0.24$ & $<0.001$ & - & - & - & 0.29 & $0.23-0.38$ & $<0.001$ & 0.58 & $0.41-0.82$ & 0.002 \\
\hline & ZMUAC gain & 0.21 & $0.16-0.28$ & $<0.001$ & 0.35 & $0.24-0.51$ & $<0.001$ & 0.32 & $0.26-0.40$ & $<0.001$ & 0.44 & $0.33-0.59$ & $<0.001$ \\
\hline
\end{tabular}

$\mathrm{CI}=$ confidence intervals; HR: hazard ratio; $\mathrm{WAZ}=$ weight for age Z-score; ZMUAC = MUAC for age Z-score 
Figure 2 shows the result of the Cox survival analysis (per outcome death) by HIV status, baseline WAZ, and the presence of edema. Children affected by any of these critical conditions-defined as HIV infection, very low weight-for-age (WAZ $<-3$ ) and kwashiorkor (presence of nutritional edema) — were more likely to die than their counterparts.
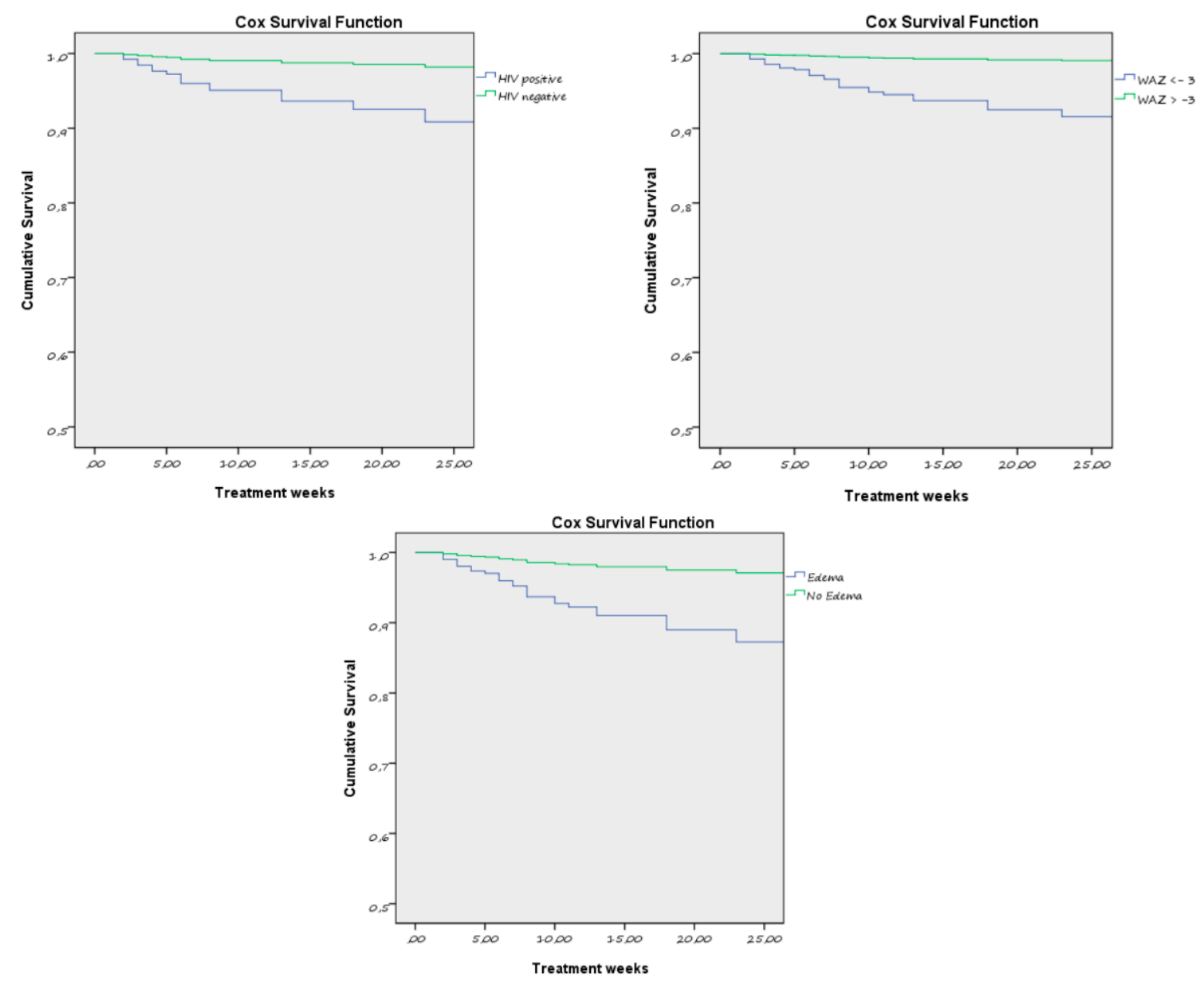

Figure 2. The Cox survival analysis. The outcome of death by HIV status, weight for age z-score, and kwashiorkor at baseline.

\subsection{Second Results: HIV Counseling and Testing}

Figure 3 presents the data on the HIV status of children at the time of discharge, comparing results with Rainbow 2012-14. The general number of children with an HIV infection decreased over the years $(7.3 \%$ vs. $4.1 \%)$ and conversely, the number of HIV negative children increased ( $67.6 \%$ vs. $78.2 \%)$, reflecting the efforts of the Zambian government in promoting HIV PMTCT after the launch of new Guidelines on HIV. In fact, at the time of data collection, the country had adopted and progressively implemented WHO Option B+, recommending a lifelong triple-combination ART for all confirmed HIV-infected children regardless of the CD4 count and/or WHO clinical stage [36].

In addition, the most incisive goal on HIV reached by the Rainbow SFPs was seen in the increased access to HIV diagnosis during the enrollment in the programs. As compared to the nearly $49 \%$ of diagnoses made in Rainbow 2012-14, nearly 79\% of new HIV diagnoses were made in Rainbow 2015-17 (30\% greater; $p<0.001)$. Among the 83 children who were HIV exposed but still without an HIV diagnosis $(9.7 \%)$, nearly $65 \%$ were less than 18 months of age, so presumably, definitive test results were not yet available. 


\section{HIV STATUS AT DISCHARGE}

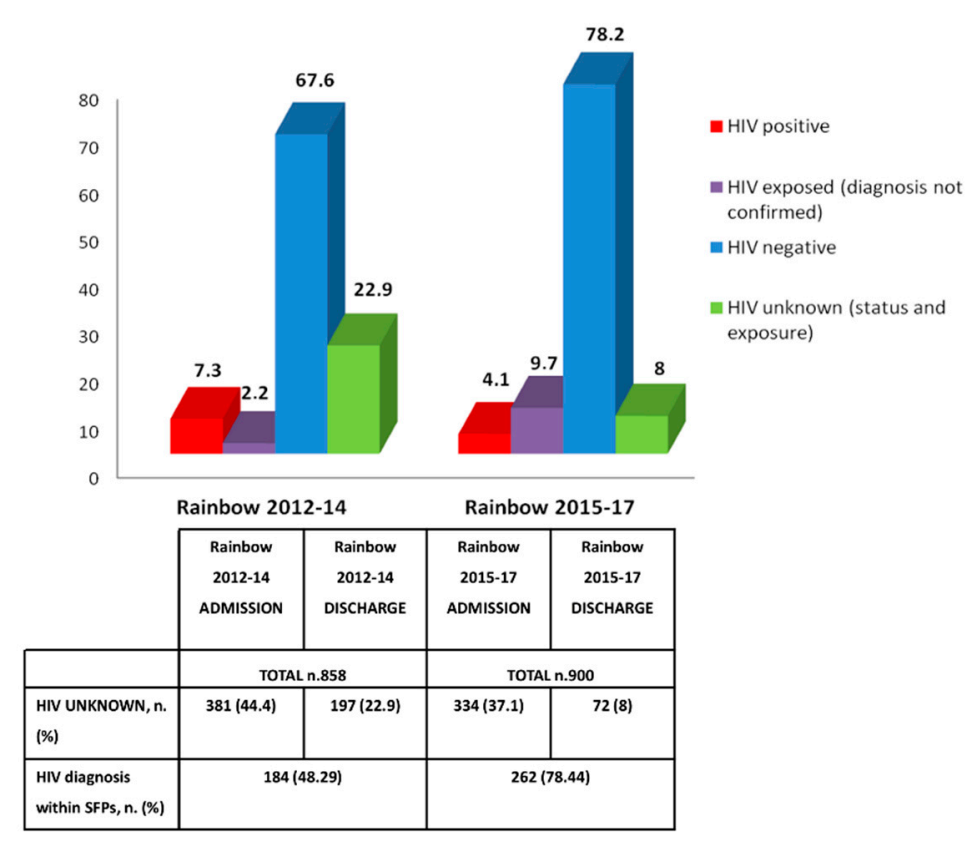

Figure 3. The HIV status at discharge: comparison between Rainbow 2012-14 and 2015-17.

\section{Discussion}

The Rainbow experience in Zambia supports the hypothesis that monitoring and evaluating activities improve the sustainability and effectiveness of community-based programs for child malnutrition that already exist and are well-implemented in the field [5,37-39]. Integrated community-based programs that promote general child malnutrition treatment and prevention, hold the potential to reduce the prevalence of acute malnutrition by reducing the incidence and enhancing treatment effectiveness $[8,40,41]$. Nutritional rehabilitation has not been considered a stand-alone intervention within nutritional programs: nutritional counseling, IYCF knowledge, health education, HIV / AIDS counseling, testing and diagnosis, immunization sensitization and awareness, control of infections and malaria, TB prevention and screening, must be integrated in CMAM protocols as these are critical primary care elements [42-44]. Providing this such innovative approach allows for the early optimization of nutritional status, with a positive impact on the prevention of acute malnutrition [23,24]. Recently, it has also been proven that combined protocol for MAM and SAM treatment with RUTF could be cost-effective [45]. Similarly, Rainbow's innovative protocol, providing an integrated approach for the treatment and prevention of MAM, SAM and underweight, has shown to be effective, culturally acceptable, and affordable, while using local food plus fortified blended flour locally produced in an area with the erratic availability of RUTF. The efficacy of high energy supplements for child malnutrition management is already well documented in the literature [25,34,46-48].

As a novel study, the present analysis also highlighted that well-trained and supervised community volunteers are capable of identifying and managing cases of uncomplicated malnutrition, providing accurate, reliable, and trustable data [49]. These results are not easily demonstrable in community programs as discussed in field reports, where data collection and analyses are often not rigorously performed [5].

As first aim of the current study, outcomes of 2015-17 met the Sphere International Standards, either in general or when considering the different types of malnutrition separately, with statistically significant improvements compared to those of 2012-14. Improving the food schedule coupled with nutritional counseling $[23,25,50]$ increased the average weight gain significantly and shortened the 
mean length of stay for recovered children, as proposed in the previous Rainbow study. Halving mortality rates was the main observable goal, in general, or when considering MAM and SAM separately. Our findings show outcomes similar to other studies evaluating community-based programs for moderate malnutrition despite, in some cases, a lower weight gain [51,52], or a better cure rate but higher mortality rates [53]. It was difficult to compare the length of stay with results from other field studies since "non-cured/non-responder" was not an outcome of Rainbow SFPs as nutritional assistance was ensured to all children until recovery occurred.

When investigating the factors contributing to negative outcomes, the Cox proportional risk analysis showed that very low weight-for-age at baseline (<-3SD), kwashiorkor and, in particular, HIV infection were the main predictors of mortality. Along with the survival risk, it is widely recognized that children affected by HIV / AIDS are at serious risk of developmental delays, which is also reported for those exposed to HIV in utero but are born uninfected, and for those whose parents are affected by HIV [54,55]. More research is needed to investigate these results within the specific Zambian context. The poor gain in anthropometric parameters (WAZ gain, weight gain, and ZMUAC gain) during nutritional rehabilitation was independently associated either with case-fatality or defaulting. This result was in line with the previous Rainbow study and highlighted the premise that the prevention and management of underweight status, considered a second priority criterion of admission, should be recognized as an essential part of the program against childhood malnutrition [23,24]. Future research on growth velocity should be performed in order to define better indices for predictors of child mortality [56].

As a second aim of this study, a significant reduction in children with an unknown HIV status at the time of discharge (nearly 35\% less) was noted, reflecting the large effort put into VCT for HIV / AIDS for which Rainbow's community volunteers were strongly trained. We underline the great importance of this result since this improvement was reached with no additional costs for the program besides routine capacity building activities (training and refresher courses). Moreover, the decreased number of children who were HIV infected over the years was in line with the country's report which stated a decline in HIV MTCT from 14.9\% in 2013 to less than 9\% in 2014 [36,57]. The efforts of the Zambian government in promoting HIV PMTCT was also supported by the increased number of HIV infected children receiving antiretroviral treatment, $70 \%$ in $2015-17$ compared to the $52 \%$ in $2012-14$. Since it is well known that the HIV infection is the most important predictor of mortality among HIV infected, especially when not treated or timely tested [58,59], we can presume that the greatest efforts in VCT and knowledge in HIV / AIDS, both at the health district and at the community level, might have contributed in lowering mortality rates within the Rainbow SFPs.

\section{Limitations of the Study}

For ethical and humanitarian reasons, the same protocol and treatment were ensured to all the children admitted in Rainbow SFP, so that in the absence of a control group we can only estimate that improvements in mortality outcomes are due to the changes made to the protocol.

In regards to RUTF consumption, unfortunately, no specific evaluations were done due to the lack of consistent information on RUTF taken and/or disruption of OTP services. We can presume that a simultaneous consumption of RUTF by children with SAM, even if at times erratic, might have contributed to their weight gain. Full collaboration and dialogue among different local stakeholders dealing with malnutrition should be therefore promoted and constantly enhanced.

Finally, we emphasize that there is still a lack of common standard protocols for evaluating the effectiveness of community-based programs delivered in non-emergency contexts, with Sphere indicators still being the main markers for the assessment of CMAM performance. Conditions for delivering CMAM programs are not the same in non-emergency and emergency contexts, and for this reason, relying only on Sphere guidelines to measure program performance may not be comprehensive enough [6]. More research is needed to identify other field-based indicators which should be included in the evaluation of the effectiveness of CMAM, such as specific indicators for underweight and 
relapse malnutrition rates. In fact, we have identified a high proportion of relapses that need further investigation, in accordance to the recent literature [60].

\section{Conclusions}

The Rainbow SFPs provide a sustainable community-based approach for the integrated treatment and prevention of malnutrition in Zambia that is effective in reduction of mortality among under-5 malnourished children, whether MAM, SAM or underweight. Moreover, Rainbow SFPs act as efficient entry points for child growth surveillance, nutrition and health promotion, facilitating access to $\mathrm{HIV} / \mathrm{TB}$ treatment and care for Zambian children.

The consistent monitoring and evaluation of the programs with the identification of critical areas and adjustments made accordingly, as well as the continuous technical assistance and support, specific trainings, and refresher courses of the community volunteers, resulted in significant gains in the process and generated positive outcomes, with the consequent enhancement of the program's performance.

When CMAM is not fully implemented or scaled-up, our results emphasize the need for nutritional programs already implemented in the field to identify coping strategies for not neglecting any form of child malnutrition, especially most severe cases. Key to the process is a holistic and multi-sectoral approach that facilitates the integration between nutrition and health, taking into account the local environment, affordable resources, and culturally accepted actions.

Author Contributions: S.M. performed the statistical analysis and interpretation of the data, drafted and wrote the manuscript, made a substantial contribution to the local implementation. G.A. supervised the study at local level, contributed to the interpretation of the data, provided critical comment and revision of the manuscript. J.K.C. reviewed the paper and provided critical comment, made a substantial contribution to the local organization. K.N.-S. reviewed and edited the manuscript, and contributed critical comments. L.P. performed the statistical analysis, contributed to the data interpretation and provided critical comment and revision of the manuscript. E.B. supervised the study, performed the statistical analysis and the interpretation of the data, provided critical comment and revision of the manuscript. All authors red and approved the final manuscript.

Funding: This research received no external funding.

Acknowledgments: We acknowledge with gratitude all the children and their guardians assisted in SFPs during these years of work. We thank the Association Pope John the 23rd and all the operators and volunteers of NGOs/CBOs involved in the nutritional program for their tremendous job in the community. We thank Clarice Ciarlantini, Marta Don, Alessia Capuano, Emanuela Alzari who helped in data collection in the field and for merging data files used in these analyses. We are particularly grateful to Elisabetta Garruti and Gloria Gozza for project management, guidance and support. We would also like to thank all the Ndola District Health Office for their constant support and advice.

Conflicts of Interest: The authors declare no conflict of interest.

$\begin{array}{ll}\text { Abbreviations } & \\ \text { AIDS } & \text { Acquired Immune Deficiency Syndrome } \\ \text { ART } & \text { Antiretroviral Therapy } \\ \text { ARV } & \text { Antiretroviral } \\ \text { CBOs } & \text { Community-based Organizations } \\ \text { CI } & \text { Confidence Interval } \\ \text { CMAM } & \text { Community-Management of Acute Malnutrition } \\ \text { CSB } & \text { Corn soya blended food } \\ \text { CTC } & \text { Community-based Therapeutic Care } \\ \text { DHMTs } & \text { District Health Management Teams } \\ \text { HAART } & \text { Highly active antiretroviral therapy } \\ \text { HEPS } & \text { High energy protein supplement } \\ \text { HIV } & \text { Human Immunodeficiency Virus } \\ \text { HR } & \text { Hazard Ratio } \\ \text { IC } & \text { Inpatient Care } \\ \text { IMAM } & \text { Integrated Management of Acute Malnutrition } \\ \text { IYCF } & \text { Infant and Young Child Feeding }\end{array}$




$\begin{array}{ll}\text { MAM } & \text { Moderate Acute Malnutrition } \\ \text { MUAC } & \text { Mid-Upper Arm Circumference } \\ \text { NGOs } & \text { Non-Governmental Organizations } \\ \text { OR } & \text { Odds Ratio } \\ \text { OTP } & \text { Outpatient Therapeutic Care } \\ \text { PMTCT } & \text { Prevention Mother-to-Child Transmission } \\ \text { RUTF } & \text { Ready-to-use Therapeutic Food } \\ \text { SAM } & \text { Severe Acute Malnutrition } \\ \text { SD } & \text { Standards Deviation } \\ \text { SFP } & \text { Supplementary Feeding Programs } \\ \text { SPSS } & \text { Statistical packages for social sciences } \\ \text { TFP } & \text { Therapeutic Feeding Programs } \\ \text { TB } & \text { Tuberculosis } \\ \text { TDRC } & \text { Tropical Diseases Research Centre } \\ \text { UNHCR } & \text { United Nations High Commissioner for Refugees } \\ \text { UNICEF } & \text { United Nations International Children's Emergency Fund } \\ \text { VCT } & \text { Voluntary counseling and testing } \\ \text { WAZ } & \text { Weight-for-Age Z-score } \\ \text { WHO World Health Organization } & \text { World Health Organization } \\ \text { WHZ } & \text { Weight-for-Height Z-score } \\ \text { WLZ } & \text { Weight-for-Length Z-score } \\ \text { ZMUAC } & \text { Mid-Upper Arm Circumference for Age Z-score } \\ & \end{array}$

\section{References}

1. Blössner, M.; de Onis, M. Malnutrition: Quantifying the Health Impact at National and Local Levels; WHO Environmental Burden of Disease Series, No. 12; World Health Organization: Geneva, Switzerland, 2005.

2. No Wasted Lives Initiative: The State of Severe Malnutrition Website. Available online: http://www. severemalnutrition.org/en/home/Ge (accessed on 12 May 2018).

3. Black, R.E.; Victora, C.G.; Walker, S.P.; Bhutta, Z.A.; Christian, P.; de Onis, M.; Ezzati, M.; Grantham-McGregor, S.; Katz, J.; Martorell, R.; et al. Maternal and child undernutrition and overweight in low-income and middle-income countries. Lancet 2013, 382, 427-451. [CrossRef]

4. Hedwig, D.; Swindale, A.; Grant, F.; Navarro-Colorado, C. Review of Community-Based Management of Acute Malnutrition (CMAM) in the Post-Emergency Context: Synthesis of Lessons on Integration of CMAM into National Health Systems; Food and Nutrition Technical Assistance (FANTA): Washington, DC, USA, 2008.

5. United Nations Children's Fund. Evaluation of Community Management of Acute Malnutrition (CMAM); Global Synthesis Report; United Nations Childre's Fund: New York, NY, USA, 2013.

6. Emergency Nutrition Network. Government Experiences of Scale-Up of Community-Based Management of Acute Malnutrition (CMAM): A Synthesis of Lessons. In Proceedings of the CMAM Conference, Addis Ababa, January 2012. Available online: http:/ / files.ennonline.net/attachments/1374/cmam-conference2012-synthesis.pdf (accessed on 12 May 2018).

7. Global Nutrition Cluster MAM Task Force. Moderate Acute Malnutrition: A Decision Tool for Emergencies. 2014. Available online: http:/ / nutritioncluster.net/?get=002086\%7C2014/07/MAM-Decision-Tool-finalJune-2014-corrected.pdf (accessed on 14 August 2018).

8. Huybregts, L.; Becquey, E.; Zongrone, A.; Le Port, A.; Khassanova, R.; Coulibaly, L.; Leroy, J.L.; Rawat, R.; Ruel, M.T. The impact of integrated prevention and treatment on child malnutrition and health: The PROMIS project, a randomized control trial in Burkina Faso and Mali. BMC Public Health 2017, 17, 237. [CrossRef] [PubMed]

9. Michelo, C.; Mugode, R. Set criteria might have high potentials in the management of severely malnourished children in Zambia, evidence from an evaluation of an Outpatient Therapeutic Care Program (OTP) in selected communities in Lusaka urban, Zambia. Med. J. Zamb. 2012, 39, 6-12.

10. World Health Statistics. Monitoring Health for the SDGs, Sustainable Development Goals; World Health Organization: Geneva, Switzerland, 2017. 
11. International Food Policy Research Institute. From Promise to Impact: Ending Malnutrition by 2030; Global Nutrition Report 2016; International Food Policy Research Institute: Washington, DC, USA, 2016.

12. World Health Organization. Global Nutrition Targets 2025: Policy Brief Series. 2014. Available online: http:/ / www.who.int/nutrition/global-target-2025/en/ (accessed on 20 June 2018).

13. Joint United Nations Programme on HIV/AIDS (UNAIDS). Country Reports. Zambia HIV and AIDS Estimates Websites; UNAIDS: Geneva, Switzerland, 2018.

14. Ministry of Health. National TB/Leprosy Program 2016 TB Notification Data; Department of Public Health: Lusaka, Zambia, 2017.

15. Chabala, C.; Somwe, S.; Kapata, N.; Chongwe, G.; Jumbe-Marsden, E. Childhood tuberculosis at the main referral hospital in Lusaka, Zambia-A five years review of registered child TB cases. In Proceedings of the 43rd Union conference on Lung Health, Kuala Lumpur, Malaysia, 19 November 2012; Volume PC-661-15.

16. Munthali, T.; Chabala, C.; Chama, E.; Mugode, R.; Kapata, N.; Musonda, P.; Michelo, C. Tuberculosis caseload in children with severe acute malnutrition related with high hospital based mortality in Lusaka, Zambia. BMC Res Notes 2017, 10, 206. [CrossRef] [PubMed]

17. Maleta, K.; Amadi, B. Community-Based Management of Acute Malnutrition (CMAM) in sub-Saharan Africa: Case studies from Ghana, Malawi and Zambia. Food Nutr. Bull. 2014, 35, S34-S38. [CrossRef] [PubMed]

18. Ministry of National Development Planning. Seventh National Development Plan 2017-2021; Ministry of National Development Planning: Lusaka, Zambia, 2017.

19. Moramarco, S.; Amerio, G.; Gozza Maradini, G.; Garuti, E. Rainbow Project: A Model to Fight Child Malnutrition in Zambia. In Turning Rapid Growth into Meaningful Growth: Sustaining the Commitment to Nutrition in Zambia; Harris, J., Haddad, L., Grütz, S.S., Eds.; Institute of Development Studies: Brighton, UK, 2014; pp. 57-61. Available online: https://opendocs.ids.ac.uk/opendocs/bitstream/handle/123456789/ 4463/Zambia\%20Special\%20Collection\%20full\%20version.pdf (accessed on 14 August 2018).

20. Moramarco, S.; Amerio, G.; Ciarlantini, C.; Kasengele Chipoma, J.; Kakungu Simpungwe, M.; Nielsen-Saines, K.; Palombi, L.; Buonomo, E. Community-based management of child malnutrition in Zambia: HIV/AIDS infection and other risk factors on child survival. Int. J. Environ. Res. Public Health 2016, 13, E666. [CrossRef] [PubMed]

21. World Health Organization. Management of Severe Malnutrition: A Manual for Physicians and Other Senior Health Workers; World Health Organization: Geneva, Switzerland, 1999.

22. Valid International. Community-Based Therapeutic Care (CTC): A Field Manual. 2006. Available online: http:/ / www.concernusa.org/content/uploads/2015/08/ctc_manual_v1_oct06.pdf (accessed on May 2018).

23. UN Refugee Agency (UNHCR)/World Food Programme (WFP). Guidelines for Selective Feeding: The Management of Malnutrition in Emergencies; UNHCR: Geneva, Switzerland, 2011.

24. Black, R.E.; Laxminarayan, R.; Temmerman, M.; Walker, N. Reproductive, Maternal, Newborn, and Child Health, 3rd ed.; Disease Control Priorities; World Bank: Washington, DC, USA, 2016; Volume 2.

25. Ashworth, A.; Ferguson, E. Dietary counseling in the management of moderate malnourishment in children. Food Nutr. Bull. 2009, 30, S405-S433. [CrossRef] [PubMed]

26. Moramarco, S.; Amerio, G.; Chafula Muyaba, L.; Bonvecchio, D.; Abramo, E.; Palombi, L.; Buonomo, E. Nutritional counseling improves dietary diversity and feeding habits of Zambian malnourished children admitted in Rainbow nutritional programs. Biomed. Prev. 2017, 1. [CrossRef]

27. World Health Organization; United Nations Children's Fund. Child Growth Standard and Identification of Severe Acute Malnutrition in Infant and Children; A Joint Statement; WHO: Geneva, Switzerland, 2009; Available online: http:/ /apps.who.int/iris/bitstream/10665/44129/1/9789241598163_eng.pdf?ua=1 (accessed on 6 March 2018).

28. Zambian Ministry of Health. DRAFT Integrated Management of Acute Malnutrition Zambia Guidelines; Zambian Ministry of Health: Lusaka, Zambia, 2012.

29. World Health Organization (WHO). Guideline: Updates on the Management of Severe Acute Malnutrition in Infants and Children; WHO: Geneva, Switzerland, 2013.

30. World Health Organization. WHO Child Growth Standards: Length/Height-for-Age, Weight-for-Age, Weight-for-Length, Weight-for-Height and Body Mass Index-for-Age: Methods and Development; WHO: Geneva, Switzerland, 2006; Available online: http:/ / www.who.int/childgrowth/standards/Technical_report.pdf (accessed on 6 March 2018). 
31. The SPHERE Project. The Sphere Handbook: Humanitarian Charter and Minimum Standards in Disaster Response, 3rd ed.; The SPHERE Project: Geneva, Switzerland, 2011; Available online: https://www.unscn.org/uploads/web/news/2011-Sphere-Project-Handbook-HumanitarianCharter-in-Humanitarian-Response.pdf (accessed on 6 March 2018).

32. WHO. World Health Organization (WHO) Anthro for Personal Computers, version 3.2.2; 2011. Software for Assessing Growth and Development of the World's Children; WHO: Geneva, Switzerland, 2010.

33. Alvarez, J.L.; Dent, N.; Browne, L.; Myatt, M.; Briend, A. Putting Child Kwashiorkor on the Map. CMAM Forum Technical Brief, 2016. Available online: http://files.ennonline.net/attachments/2485/PuttingKwashiorkor-on-the-Map.pdf (accessed on 10 March 2018).

34. Matilsky, D.K.; Maleta, K.; Castleman, T.; Manary, M.J. Supplementary feeding with fortified spreads results in higher recovery rates than with a corn/soy blend in moderately wasted children. J. Nutr. 2009, 139, 773-778. [CrossRef] [PubMed]

35. Akparibo, R.; Harris, J.; Blank, L.; Campbell, M.J.; Holdsworth, M. Severe acute malnutrition in children aged under 5 years can be successfully managed in a non-emergency routine community healthcare setting in Ghana. Matern. Child Nutr. 2017, 13. [CrossRef] [PubMed]

36. Government of the Republic of Zambia Ministry of Health. Lifelong Antiretroviral Drugs (ARV's) for All HIV Positive Pregnant Women in Zambia. Policy Guidelines for Health Facilities in Zambia; 2013. Available online: https:/ / www.medbox.org/zm-guidelines-hiv-tb / lifelong-antiretroviral-drugs-arvs-forall-hiv-positive-pregnant-women-in-zambia/preview? (accessed on 3 April 2018).

37. Ruel, M.T.; Menon, P.; Habicht, J.P.; Loechl, C.; Bergeron, G.; Pelto, G.; Arimond, M.; Maluccio, J.; Michaud, L.; Hankebo, B. Age-based preventive targeting of food assistance and behavior change and communication for reduction of childhood undernutrition in Haiti: A cluster randomized trial. Lancet 2008, 371, 588-595. [CrossRef]

38. Collins, S.; Sadler, K.; Dent, N.; Khara, T.; Guerrero, S.; Myatt, M.; Saboya, M.; Walsh, A. Key issues in the success of community-based management of severe malnutrition. Food Nutr. Bull. 2006, 27, S49-S82. [CrossRef] [PubMed]

39. Dent, N.; Deconinck, H.; Golden, K.; Brown, R.; Walsh, A. Information-sharing to improve learning about Community-Based Management of Acute Malnutrition (CMAM) and its impact. Food Nutr. Bull. 2014, 35, S86-S90. [CrossRef] [PubMed]

40. DiGirolamo, A.M.; Stansbery, P.; Lung'aho, M. Advantages and challenges of integration: Opportunities for integrating early childhood development and nutrition programming. Ann. N. Y. Acad. Sci. 2014, 1308, 46-53. [CrossRef] [PubMed]

41. Maust, A.; Koroma, A.S.; Abla, C.; Molokwu, N.; Ryan, K.N.; Singh, L.; Manary, M.J. Severe and moderate acute malnutrition can be successfully managed with an integrated protocol in Sierra Leone. J. Nutr. 2015, 145, 2604-2609. [CrossRef] [PubMed]

42. Patel, D.; Matyanga, P.; Nyamundaya, T.; Chimedza, D.; Webb, K.; Engelsmann, B. Facilitating HIV testing, care and treatment for orphans and vulnerable children aged five years and younger through community-based early childhood development playcentres in rural Zimbabwe. J. Int. AIDS Soc. 2012, 15, 17404. [CrossRef] [PubMed]

43. Tomlinson, M.; Skeen, S.; Marlow, M.; Cluver, L.; Cooper, P.; Murray, L.; Mofokeng, S.; Morley, N.; Makhetha, M.; Gordon, S.; et al. Improving early childhood care and development, HIV-testing, treatment and support, and nutrition in Mokhotlong, Lesotho: Study protocol for a cluster randomized controlled trial. Trials 2016, 17, 538. [CrossRef] [PubMed]

44. Scarcella, P.; Moramarco, S.; Buonomo, E.; Nilesen-Saines, K.; Jere, H.; Guidotti, G.; Palombi, L.; Marazzi, M.C. The impact of malaria on child growth: Anthropometric outcomes in a pediatric HIV-exposed cohort in Malawi. Biomed. Prev. 2016, 1. [CrossRef]

45. Bailey, J.; Lelijveld, N.; Marron, B.; Onyoo, P.; Ho, L.S.; Manary, M.; Briend, A.; Opondo, C.; Kerac, M. Combined Protocol for Acute Malnutrition Study (ComPAS) in rural South Sudan and urban Kenya: Study protocol for a randomized controlled trial. Trials 2018, 19, 251. [CrossRef] [PubMed]

46. De Pee, S.; Bloem, M.W. Current and potential role of specially formulated foods and food supplements for preventing malnutrition among 6- to 23-month-old children and for treating moderate malnutrition among 6- to 59-month-old children. Food Nutr. Bull. 2009, 30, S434-S463. [CrossRef] [PubMed] 
47. Iuel-Brockdorf, A.S.; Draebel, T.A.; Ritz, C.; Fabiansen, C.; Cichon, B.; Brix Christensen, V.; Yameogo, C.; Oummani, R.; Briend, A.; Michaelsen, K.F.; et al. Evaluation of the acceptability of improved supplementary foods for the treatment of moderate acute malnutrition in Burkina Faso using a mixed method approach. Appetite 2016, 99, 34-45. [CrossRef] [PubMed]

48. Fabiansen, C.; Yaméogo, C.W.; Iuel-Brockdorf, A.S.; Cichon, B.; Rytter, M.J.H.; Kurpad, A. Effectiveness of food supplements in increasing fat-free tissue accretion in children with moderate acute malnutrition: A randomised $2 \times 2 \times 3$ factorial trial in Burkina Faso. PLoS Med. 2017, 14, e1002387. [CrossRef] [PubMed]

49. Alvarez Morán, J.L.; Alé, F.G.; Rogers, E.; Guerrero, S. Quality of care for treatment of uncomplicated severe acute malnutrition delivered by community health workers in a rural area of Mali. Matern. Child Nutr. 2017, 14. [CrossRef] [PubMed]

50. Briend, A.; Prinzo, Z.W. Dietary management of moderate malnutrition: Time for a change. Food Nutr. Bull. 2009, 30, S265-S266. [CrossRef] [PubMed]

51. Somassé, Y.E.; Bahwere, P.; Laokri, S.; Elmoussaoui, N.; Donnen, P. Sustainability and scaling-up analysis of community-based management of acute malnutrition: Lessons learned from Burkina Faso. Food Nutr. Bull. 2013, 34, 338-348. [CrossRef] [PubMed]

52. Ackatia-Armah, R.S.; McDonald, C.M.; Doumbia, S.; Erhardt, J.G.; Hamer, D.H.; Brown, K.H. Malian children with moderate acute malnutrition who are treated with lipid- based dietary supplements have greater weight gains and recovery rates than those treated with locally produced cereal-legume products: A community-based, cluster-randomized trial. Am. J. Clin. Nutr. 2015, 101, 632-645. [CrossRef] [PubMed]

53. Karakochuk, C.; Van den Briel, T.; Stephens, D.; Zlotkin, S. Treatment of moderate acute malnutrition with ready-to-use supplementary food results in higher overall recovery rates compared with a corn-soya blend in children in southern Ethiopia: An operations research trial. Am. J. Clin. Nutr. 2012, 96, 911-916. [CrossRef] [PubMed]

54. Sherr, L.; Mueller, J.; Varrall, R. A systematic review of cognitive development and child human immunodeficiency virus infection. Psychol. Health Med. 2009, 14, 387-404. [CrossRef] [PubMed]

55. Buonomo, E.; Scarcella, P.; Tembo, D.; Giuliano, M.; Moramarco, S.; Palombi, L.; Nielsen-Saines, K.; Mancinelli, S.; Marazzi, M.C. Malnutrition decreases the odds of attaining motor milestones in HIV exposed children: Results from a paediatric DREAM cohort. Epidemiol. Prev. 2015, 39, 108-112. [PubMed]

56. O'Neill, S.M.; Fitzgerald, A.; Briend, A.; Van den Broeck, J. Child mortality as predicted by nutritional status and recent weight velocity in children under two in rural Africa. J. Nutr. 2012, 142, 520-525. [PubMed]

57. The National HIV/AIDS/STI/TB Council and Republic of Zambia. Monitoring the Declaration of Commitment on HIV and AIDS and the Universal Access. Submitted to the United Nations General Assembly Special Session on HIV and AIDS; Zambia Country Report. 2015. Available online: http: / / www.unaids.org/sites/default/ files/country / documents/ZMB_narrative_report_2015.pdf (accessed on 6 March 2018).

58. Asafo-Agyei, S.B.; Antwi, S.; Nguah, S.B. HIV infection in severely malnourished children in Kumasi, Ghana: A cross-sectional prospective study. BMC Pediatr. 2013, 13, 181. [CrossRef] [PubMed]

59. Frigati, L.; Archary, M.; Rabie, H.; Penazzato, M.; Ford, N. Priorities for decreasing morbidity and mortality in children with advanced HIV disease. Clin. Infect. Dis. 2018, 66, S147-S151. [CrossRef] [PubMed]

60. Somassè, Y.E.; Dramaix, M.; Bahwere, P.; Donnen, P. Relapses from acute malnutrition and related factors in a community-based management programme in Burkina Faso. Matern. Child Nutr. 2016, 12, 908-917. [CrossRef] [PubMed]

(C) 2018 by the authors. Licensee MDPI, Basel, Switzerland. This article is an open access article distributed under the terms and conditions of the Creative Commons Attribution (CC BY) license (http://creativecommons.org/licenses/by/4.0/). 